\title{
La vida y el alma venecianas
}

La Universidad de Chile, movida de un alto espirifu de renovación. ha ofrecido su cátedra a algunos de los más eminentes prolesores europeos. Los cursos y conferencias que ellos han dictado en el aula de la Universidad Central constituyen una de las más elevadas manifesfaciones de la cultura moderna en nuestro pais.

Hoy. quien ocupa esa tribuna universitaria. invitado por la Universidad y el Gobierno. es el reputado hisforiador, miembro del Instituto de Francia, profesor de la Sorbona. M. Charles Diehl.

M. Diehl ha esfudiado con especialidad esa época de transición. interesantisima para la historia de la culfura humana, que es el fin del Imperio de Oriente y el comienzo de la era renacentisfa. Sus obras. Byzance. Grandeur ef decadence., Une République patricienne. Venises, son uno de los frutos más excelentes de la moderna escuela histórica francesa.

Como un homenaje al distinguido universitario. y como un ofrecimiento del mayor interés para nuestros lectores, inserfamos. en las páginas siguientes. el capitulo central de la última de las obras mencionadas. aun no vertidas a nuestra lengua.

I. Las fiestas de Venecia.-La vida privada y las costumbres.-II. El alma veneciana.-La preocupación por el comercio.-La atención de las cuestiones religiosas.-Venecia y la Iglesia.-El patriotismo veneciano.-Las virtudes del veneciano.-El dux Andrés Dandolo.-La cultura intelectual.

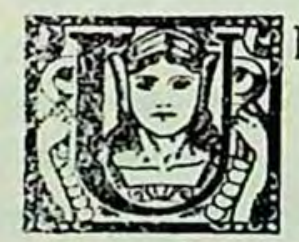

NA ciudad tal como era Venecia en el siglo XV. rica, elegante, apasionada del lujo, el esplendor, el colorido, ofrece un cuadro maravilloso a las fiestas magnificas. Por otra parte. en la ciudad de San Marcos sucedianse toda clase de solemnidades. civiles y religiosas, políticas y militares, en que se complacian los venecianos, porque aun eran un medio para exaltar la gloria de la ciudad. su orgulloso poderio y el amor profundo de los ciudadanos por la patria. 


\section{LAS FIESTAS DE VENECIA}

Desde muy antiguo, los venecianos practicaban el tiro del arco, sejercicio muy útil, dice un documento, y de mucho provecho para nuestro paiss. puesto que mantenía el vigor corporal y formaba una raza robusta para la defensa de la ciudad. Esta vieja costumbre subsistía aún en el siglo XIV. Todos los venecianos. desde los quince hasta los treinta años, estaban inscritos en las compañías de arqueros, y tres veves por año, en San Nicolás de Lido, se celebraban con gran pompa solemnes concursos. A este mismo propósito obedecían las luchas con bastones y los pugilatos, subsistentes hasta el siglo XVIII, y en los cuales, sobre los puentes sin parapeto, enfrentábanse,- con el peligro de ser arrojados al canal,los jóvenes de los diversos barrios de la ciudad. El mismo culto de la fuerza lísica manifestábase en los ejercicios de equilibrio y agilidad llamados Forze d'Ercole, en las que ingeniosos acróbatas edificaban pirámides humanas, construidas a menudo sobre el apoyo vacilante de un piso de madera sostenido entre dos barcas. Y, por fin, desde los comienzos del siglo XIV, las regatas ocupaban lugar importante en la ciudad de las lagunas. y hacia fines del siglo XV. las mismas mujeres comenzaron a participar en ellas.

Si los canales y la laguna ofrecian un maravilloso campo a la actividad popular, la Piazzetta y la plaza de San Marcos, eran, para las otras fiestas, el más admirable de los teatros. Se ofrecian alli combates de toros, nó a la usanza española, sino que se sostenía a la bestia por una cuerda que se le ataba a las astas y se la hacía atacar por vigorosos perros. Los venecianos se entusiasmaban con estos combates y el mismo dux no desdeñaba venir a admirarlos desde los balcones de su Palacio.

Otros días, eran torneos magníficos, para los cuales la gran plaza se presentaba totalmente decorada de pinturas, escudos y estandartes, toda resplandeciente con el esplendor de las armas, el brillo de los vestidos y la arrogante apostura de los caballos. En la logia edificada bajo los grandes portales de San Marcos, aposentábase el dux con su acompañamiento, y la magnificencia del espectáculo atraía innumerable concurrencia. Petrarca nos ha conservado el suntuoso recuerdo de la fiesta celebrada en 1364, cuando el rey de Chipre. Pedro II. huésped entonces de la República, quebrara magnificamente su lanza; en 1413. con ocasión de ser elegido dux Tomás Mocenigo, el torneo no fué menos hermoso: más de sesenta mil personas asistieron a él.

Eran los venecianos pueblo muy piadoso; por lo menos si hemos de atenernos a las manifestaciones externas de la religión: .Es la ciudad, dice Commynes, en donde el servicio de Dios se celebra más solemnemente, y si bien pudiera haber alli otras faltas, creo que Dios les otorga su ayuda, por la reverencia con que se dedican al servicio de la Iglesia.. Ciertamente, las fiestas religiosas eran en Venecia numerosas y espléndidas. Las festividades en honor 
de la Virgen se celebraban con particular pompa, semejantes a las cuatro commemoraciones de San Marcos, que recordaban la pasión del apóstol. la translación de sus reliquias de Alejandría a Venecia, su aparición maravillosa en el siglo XI y la consagración de la basílica elevada a su gloria. San Esteban y San Juan. San Lorenzo y San Miguel, San Martin y San Nicolás, compartian. después del evangelista, la devoción de los venecianos. El cuadro famoso de Gentile Bellini muestra muy bien la magnificencia de las procesiones que en los dias de fiestas desplegaban su cortejo suntuoso en la plaza de San Marcos.

Otras fiestas, aun más caracteristicas del espiritu veneciano, conmemoraban los triunfos de la República y las más gloriosas jornadas de su historia. El primero de Febrero era la fiesta delle Marie, de la cual también Commynes nos ha conservado el recuerdo, y en que se celebraba el rescate de las novias venecianas raptadas en el siglo X en la Catedral de San Pedro de Castello por los piratas de Istria. Aquel dia. doce jóvenes patricias, elegidas entre las más bellas de la ciudad, iban. magnificamente vestidas y coronadas de oro, a la Catedral primero y luego a San Marcos, donde se oficiaba una misa solemne: después, escoltando al dux, recorrian el gran canal y se dirigian a Santa María Formosa, donde se realizaba una nueva ceremonia en honor de los habitantes de esta parroquia, a quienes la tradición atribuia importante participación en la victoria rememorada. Subsistió esta fiesta hasta 1379: las desgracias de la guerra de Chioggia la interrumpieron hacia esta época, y de ella sólo se conservaba hacia fines de la República, la costumbre de que el dux fuera anualmente a recibir de manos del cura de la iglesia los sombreros de paja dorada y el vino de Malvoisie, que le ofrecian los habitantes del barrio de Santa Maria Formosa.

En el día de la Ascensión celebrábanse los triunfos más memorables. Era ésta la fecha en que antiguamente Pedro II Orseolo habia abandonado a Venecia para conquistar la Dalmacia: era el dia en que. más tarde. según la leyenda. las galeras venecianas habían derrotado la flota de Federico Barbarroja, y en que Alejandro III. como recompensa, había concedido a la República el imperio del Adriático. En memoria de estos grandes acontecimientos, cada año. a partir del siglo XIII, el dux celebraba con gran brillo sus esponsales con el mar. Sobre el Bucentaure,en su suntuoso ropaje de púrpura y oro. se dirigía al paso de Lido. y alli, arrojando su anillo de oro a las aguas. pronunciaba la fórmula solemne: -Te desposamos, oh mar, en señal de verdadero y perpetuo dominio. Después cantábase la misa y, en la noche. terminaba la fiesta con un brillante banquete en el Palacio.

El Jueves Santo se festejaba la victoria lograda en el siglo XII sobre el patriarca de Aquilea. Desde entonces, el patriarca enviaba cada año y en aquel día, como un tributo a Venecia, doce enormes panes y doce puercos cebados. Con gran ceremonia, en la plaza de San Marcos, en medio de los fuegos artificiales y de las aclamaciones del pueblo, degollábanse los animales, mientras en el Palacio ducal, el dux y sus consejeros destrozaban con una maza de hierro unos pequeños castillos de madera, símbolo de las fortalezas de Friul.

Igualmente se celebraba el recuerdo de la conquista de Constantinopla y el 
dia de San Vital, en que habia sido aniquilada la sedición de Bajamonte Tiépolo, y el de San Isidoro. cuando fuera condenado Martino Falier. La elección del dux era oportunidad para otras festividades. banquetes. procesiones en la plaza, oficios solemnes en la basilica, entretenimientos populares. Ninguna ocasión dejaba escapar Venecia para exaltar su gloria. su riqueza y su poderio: complaciase. sobre todo, en deslumbrar a los príncipes y a los reyes que en multitud la visitaban en los siglos XIV y XV. Al rey de Chipre, que había venido en 1362. sucedía, en 1367. el emperador Carlos IV: luego, eran los principes italianos, los soberanos de Milán, de Mantua, de Ferrara, los archiduques de Austria, los duques de Borgoña, los emperadores de Constantinopla Manuel II (1403) y Juan IV (1437): eran el hijo del rey de Portugal y el hijo del rey de Aragón, el arzobispo de Wéstminster y el duque de Baviera, el emperador Federico III, que vino dos veces (1452 y 1468). y tantos otros más. Para recibir a tales huéspedes, que daban mayor brillo a su gloria, no encontraba la República bastantes esplendores. Todos regresaban deslumbrados por la belleza de los vestidos, la magnificencia de las joyas, el incomparable poder de la ciudad de San Marcos. Venecia, en esta época, era el hospedaje de los reyes.

Por estos años también, otra fiesta, durante algunos meses, tenía a la ciudad en regocijo: era el famoso carnaval de Venecia. Desde el siglo XIII, aparece la costumbre de enmascararse en ciertos dias de fiesta. Una ley de 1339 prohibe los disfraces deshonestos e impide la entrada de los enmascarados a las iglesias y monasterios de mujeres. donde, a favor de los disfraces. se decian y cometian gruesos despropósitos. Pero estas mismas reservas prueban que en ciertos dias era permitido el uso de las máscaras. Estas estaban tan generalizadas en el siglo XV. que los fabricantes dedicados a este ramo formaban un grupo separado en la gran corporación de los pintores.

Se ven, en los cuadros en que Carpaccio pintó la leyenda de Santa Ursula. jóvenes elegantes, con estrechas calzas bordadas de plata y oro. con justillos magnificos y largos cabellos flotantes cubiertos de una toca roja: son los compañeros de la Calza, flor de la juventud y la elegancia venecianas, cuyas corporaciones. de diversos nombres, tenían en cierto modo el cargo oficial de organizar las fiestas públicas. Cumplian su misión con un arte delicado y fastuoso; realzaban asi con un nuevo esplendor el maravilloso cuadro de Venecia; era una nueva forma de contribuir al prestigio y a la gloria de la ciudad.

LA VIDA PRIVADA Y LAS COSTUMBRES. - Ha de imaginarse que el lujo de los particulares en nada cedia al lujo público. A la magnificencia de los aposentos, en que a veces la decoración de una sola pieza valia, según el testimonio de un viajero. más de once mil ducados de oro, correspondía la riqueza de los tocados femeninos. que hacian a las patricias venecianas comparables a la duquesa de Milán o a la reina de Francia. Sin duda, en tiempos muy remotos. habia en Venecia mujeres de espíritu austero y grave, como aquella dogaresa Felicita Michieli, cuyo epitafio, en el nártex de San Marcos, recuerda que era pia- 
dosa y bienhechora, de palabra agraciada, modesta y sin ostentaciones, y que la belleza de su alma se transparentaba en la dulzura de su rostro. Pero, desde el siglo XI. las costumbres habían cambiado. Las patricias de Venecia juzgaban que la ostentación de sus encantos era un homenaje rendido a la nobleza de sus familias y a la gloria de la ciudad. No temían dirigirse al mismo Papa (algunas curiosas súplicas del siglo XV lo atestiguan). a fin de que las autorizara, a pesar de las prohibiciones del patriarca, para llevar sus adornos y pedrerias, tanto por el honor de sus casas, dice el texto. como por los cuidados de su propia belleza.

En la Venecia de los siglos XIV y XV. la mujer ocupaba lugar prominente: y gran trabajo tenia la ley en refrenar en algo el lujo de sus vestidos y en asegurarle protección suficiente. En esta ciudad rica, elegante y mundana. Ilena de esclavos de las costumbres ligeras y de innumerables cortesanas. (omnino sunt necessarie in terra ista, dice un decreto de 1360). era grande la corrupción y el sentido moral harlo limitado. Muchas cosas vergonzosas y deshonestas, decia un acuerdo del Gran Consejo en 1315, ocurren en la plaza de San Marcos, bajo el pórtico y en la Iglesia misma. Los más grandes daban el ejemplo, y. a pesar de las severidades de la justicia, con mucha frecuencia encontraban imitadores. Escalamientos de balcones, raptos, violencias, familiaridades públicas y escandalosas, matrimonios irregulares, eran casos ordinarios en la vida veneciana. El amor era un dios poderoso cuyos golpes ni las gentes más graves evitaban: testimonio es la aventura que, con gran escándalo de los contemporáneos. condujo al dux Andrés Dándolo a los pies de la hermosa Isabel Fieschi. Filtros, conjuros mágicos, prácticas de brujeria para hacerse amar, eran en Venecia cosas de uso corriente. La ciudad tenía en toda la Italia una reputación demasiado enojosa. Con muy buena voluntad. los poetas cómicos glosaban las complacencias de las mujeres de Venecia, smás ávidas, dice un autor del siglo XIV. de carne fresca que de pan. La ciudad de San Marcos aparecía como un lugar clleno de emboscadas, como la sentina de todas las riquezas y de todas las corrupciones.

Asi pagaba Venecia el precio de su prosperidad económica y del contacto que su comercio le creaba con todas las razas del universo. Tenía, en muchos otros respectos todavía. muy mala reputación. Ya en el siglo XIII. Fra Salim bene escribía acerca de los venecianos: Son hombres codiciosos, supersticiosos y tenaces, y desearían, si lograrlo pudiesen, subyugar al mundo entero. Tratan duramente a los mercaderes que los visitan, vendiéndoles muy caro lo que éstos desean comprar: perciben, además. sobre las personas mismas y sobre los diversos puntos del territorio. fuertes derechos de peajes. Juan Villani. en el siglo XIV. no los trataba de mejor suerte. llamándolos cuna raza pérfida, proveniente de la sangre de Antenor, el que traicionó a Troya, su patria. Boccacio declaraba a Venecia casilo de toda perversidad. y le reprochaba su ambición. su orgullo, su tiranía. Ciertamente, otros la juzgaban con más benevolencia. y Petrarca afirmaba que eno habia lugar en donde un hombre amigo de la tranquilidad y de la virtud pudiera complacerse más que en esta muy noble Venecia. 
En resumen, sus ambiciones económicas y politicas valian a los venecianos, y nó sin razón, criticas muy duras. No obstante, un fondo severo de virtudes civicas exaltaba el alma veneciana y le daba una belleza singular.

\section{II}

\section{EL ALMA VENECIANA}

En el mensaje redactado por el Senado en 1374 para señalar al baile de Constantinopla la conducta que debia observar. léese una expresión caracteristica: el embajador. en toda circunstancia, deberá cobrar por el provecho y el honor de Venecia, (ad proficuum ef honorem Veneciarum). La misma fórmula se halla en el juramento que todo funcionario de la República prestaba antes de tomar posesión de su cargo o mando. Resume muy exactamente el deber señalado a la actividad económica, a la vida política y a la vida de todos los ciudadanos venecianos. Como en un lema, el doble aspecto del alma veneciana aparece en esas pocas palabras: riguroso cuidado de los intereses materiales y de la grandeza política de la ciudad, y. por sobre todo otro propósito, una ardiente y patriótica consagración a su grandeza moral y a su gloria.

LA ATENCIÓN DEL COMERCIO.--En todo veneciano aparece desde luego una atención primordial, esencial: la de los intereses comerciales de la República. Para extender el campo de acción de este comercio, para acrecentar el imperio colonial de la ciudad, para adquirir dinero y crear la riqueza, un veneciano jamás sufrió grandes escrúpulos de conciencia. Poco le importaba, si habia algún provecho que esperar, el tráfico con los musulmanes, asi fuese en traición de la cristiandad; poco le importaba procurar a los infieles materias prohibidas, o dedicarse a la trata de esclavos. siempre que este comercio le resultara remunerador. Para abrirse nuevos mercados, para cerrarlos a sus competidores, los venecianos desplegaban una energía prodigiosa: todos los medios. brutalidades, violencias, les parecian buenos contra los que pretendian resistirlos.

Un notable ejemplo de la manera como el cuidado de los intereses de Venecia dominaba toda otra consideración en las almas venecianas, aun en las más piadosas, aparece en el libro de Marino Sanudo el viejo, titulado: Secreta fidelium crucis. En el siglo XIV. la idea de las cruzadas no habia dejado de preocupar al mundo cristiano; los autores de la época esforzábanse en hallar la solución de este difícil problema. La de Sanudo es particularmente digna de atención por el cuidado con que quiere conciliar los intereses de este mundo y los del otro, y. persiguiendo siempre la liberación del Santo Sepulcro, asegurar a Venecia el predominio del comercio de la India y de la China. ¿Qué proponia. en efecto. este veneciano? A sus ojos, el Egipto aparece como el centro viviente del Islam. Conquistarlo por las armas sería, sin duda, el partido más ventajoso para Venecia; pero la empresa es difícil, más bien irrealizable. Por lo menos. se podria arruinar su potencia. desviando hacia otras regiones, la Siria 
y la Grecia, el comercio de Oriente, de donde obtiene su riqueza. Sanudo aconseja, para lograr este fin, todo un sistema de derechos prohibitivos y un bloqueo - de carácter netamente napoleónico-. que hace pensar en el bloqueo continental. Es algo significativo y característico ver a un veneciano. gran mercader y hombre de Estado a la vez, resolver por medios puramente económicos el más delicado de los problemas religiosos.

De tal suerte, la atención de los intereses particulares y la energía individual para el comercio, se confunden con el interés superior del Estado y se subordinan a èl. Es un carácter que conviene recordar y que se halla en todas las manifestaciones del espíritu veneciano, la subordinación voluntaria de los intereses particulares al servicio y a la grandeza de la República.

LA ATENCIÓN DE LAS CUESTIONES RELIGIOSAS.-Es interesante darse cuenta de cómo en el alma veneciana estos sentimientos se comportan con otros deberes que los hombres de la Edad Media sentian con fuerza singular, los deberes de la piedad y de la religión. Los venecianos, lo sabemos, eran piadosos. Es suficiente. para comprender con qué profundidad dominaba ciertas almas la emoción religiosa. contemplar las adorables y tiernas madonas que ha pintado un Giovanni Bellini. Pero su piedad era también de carácter práctico: sentimos siempre en ella, como una oculta idea práctica, el pensamiento de que un capital religioso es, para un Estado. una luerza, por lo menos tanto como un capital material. Una de las grandes inquietudes de los venecianos fué siempre conquistar reliquias de santos para su ciudad: desde las de San Marcos, hasta tantas otras que obtuvieron o que se apropiaron en el curso de los siglos XII y XIII. Es preciso leer, en los relatos que cuentan la traslación de los cuerpos sagrados, las rogativas llenas de una ingenua habilidad, mediante las cuales pretendian seducir al santo para atraerlo a Venecia. A San Nicolás de Myra dicen devotamente los fieles, en el momento de transladar sus restos venerados: .Venecia, tu hija, te llama; arde en deseos de verte. santo padre San Nicoláss. A San Isidoro se le asegura que encontrará, llegando a la ciudad de las lagunas. la más augusta de las compañias: San Marcos y San Esteban. San Hermágoras y San Nicolás. El autor de la translación de San Nicolás, feticitando a su patria por haber sabido asegurarse conjuntamente el patronato de San Marcos. defensor en las batallas, y el de San Nicolás, protector en las tempestades, agrega estas rrases características: TTú has conquistado uno de estos Santos. Venecia. por medio de un ingenioso engaño: el otro. por un hermoso golpe de fuerza. $Y$. sin embargo, no hay en esto ni engaño ni robo, puesto que no es una intención perversa la que ha guiado tus actos. sino el respeto de los Santos y el celo de la Religión. Para un veneciano, el fin justificaba los medios. aun en las cuestiones de la piedad, siempre que este fin fuera el interés y la gloria de la ciudad.

Seguramente, la devoción a las reliquias era algo muy generalizado durante la Edad Media. y no valdría la pena anotarla si no hubiera tomado en Venecia un carácter muy particular. No solamente era una obra piadosa enriquecer a la ciudad con algún santo despojo, sino que el orgullo veneciano se complacia en imaginar 
que los Santos sentian placer especial al ser trasladados, aun por la violencia, a la ciudad de San Marcos. El relato que en su crónica hace el dux Andrés Dandolo del descubrimiento del cuerpo de San Tarasio, es, a este respecto, muy digno de notarse. En un pais de Oriente, durante una estadia, tres marinos venecianos entran en una iglesia; uno de ellos oye una voz: Saca de aqui este cuerpo santo y llévalo contigos. El hombre ora: después busca, y cerca del altar, advierte un icono de San Terasio y una estof́a adosada al muro, y, detrás de la estofa, descubre una pieza donde las reliquias del Santo aparecen expuestas entre dos lámparas. Pónese entonces al trabajo; quiere separar el cuerpo sagrado, y éste, dice la leyenda, a la solicitación de la mano del veneciano, parece prestarse como un cuerpo vivo y decir a su raptor: Llévame; estoy pronto a acompañartes. Los venecianos se llevan consigo la reliquia. En vano los monjes griegos corren tras ellos amenazantes y llorosos: .Hombres crueles, devolvednos nuestro santo padre; no podréis alejaros de aquí si no nos lo restituís.. Vana predicción. Las galeras aparejan y. en la tempestad, el navio que conduce el precioso cuerpo sparecía, dice el texto. nadar como un cisne sobre las ondas del mar. Andrés Dandolo, que refiere esta historia. no se siente poco orgulloso. a pesar de los muchos años transcurridos, de que el patrón de la dichosa nave haya sido uno de sus abuelos.

De tal suerte. las cosas de la fe tienen en Venecia por objeto primero servir los intereses del Estado. Las preocupaciones religiosas se confunden y se armonizan tan bien con las inquietudes profanas, que los clérigos se cuentan entre los más ricos negociantes de la República, y, la Iglesia, como la nobleza, se honra trabajando por la grandeza económica de la ciudad. Ciertamente, la piedad veneciana es real y sincera: manifiéstase en la construcción de iglesias, conventosíy hospitales. en ceremonias pomposas, en mil fundaciones muy dignas de toda alabanza. Pero es una piedad extraordinariamente razonable, que no da en los excesos del misticismo ni en los de la superstición. Cuando, en el siglo XIV. hacían estragos en el Occidente cristiano las procesiones de disciplinantes, el gobierno de la República las prohibió resueltamente en Venecia, y se refiere que en 1399. un servidor de los Diez, al encontrar uno de esos cortejos prohibidos, no tuvo el menor escrúpulo en arrancar el crucifijo de manos del que lo conducia y en arrojarlo brutalmente por tierra. Lejos de castigarlo. la Señoria desterró a los jefes del movimiento. Análogamente, en 1379. durante la guerra de Chioggia, la República llamó a todos los religiosos a servir bajo las armas como los demás ciudadanos y proscribió a los que rehusaron servirla. Era porque en Venecia el Estado proclamaba audazmente su superioridad sobre la Iglesia y pretendia imponerle su autoridad.

VENECIA Y LA IGLESIA.-Desde los primeros tiempos de la República, el dux intervenía. confirmando la elección, en la designación de patriarca de Grado. y conservó este derecho hasta que, en 1451, fué suprimido el patriarcado de Grado y el título de patriarca atribuído al obispo de Venecia. Asimismo, los obispos del territorio veneciano cuya elección no se verificaba sino después de la autorización del Estado, recibian del dux la investidura de sus cargos; todavía, a partir de 1391. Tueron elegidos por el Senado. La supervigilancia del clero secular per- 
tenecia al Consejo de los Diez; la del clero regular a partir de 1521, a los provisores de los monasterios; y la ley velaba atentamente. reclamando la policia de las instituciones eclesiásticas, a fin de que los intereses del estado no fueran lesionados por las cuestiones religiosas. El Estado se empeñaba en limitar las inmunidades eclesiásticas (el clero estaba sujeto a los mismos impuestos que el resto de los ciudadanos) y el desarrollo de la mano-muerta: sometía al clero. salvo en las causas espirituales, a los mismos tribunales que los laicos; aun más. fiscalizaba las deliberaciones del Tribunal de la Inquisición. a las cuales asistian tres senadores que llevaban el titulo de inquisidores para la herejia; se reservaba el derecho de examinar. antes de ser publicados. las órdenes de la Congregación: trataba de ejercer ante todo, sobre las personas y las cosas de la religión, una autoridad indiscutida en las cuestiones temporales. El príncipe, declaraba un dux al nuncio pontificio, no reconoce en las cuestiones temporales otro superior que Dioss. El Estado excluia de los empleos públicos a todas las personas de la Iglesia y aun a los nobles que gozaban de algún beneficio eclesiástico: y eran tales los temores por la influencia de la Iglesia en los asuntos de la ciudad. que en el Gran Consejo y en el Senado. cuando se discutia alguna cuestión relativa al clero o a las relaciones con Roma, todos los que tenían parientes o afines en las órdenes, todos aquéllos a quienes sus tradiciones de familia señalaban como partidarios paladinos de la Santa Sede, quedaban excluidos por esta fórmula que la ley prescribía: Fuora Papalisti. (Fuera los papistas).

Es que. en efecto, a pesar del respeto exterior que Venecia profesaba por el papado, y aunque se enorgulleciera de llevar el nombre de cciudad apostólica y santa.. mantenía siempre, respecto de la Santa Sede, una independencia firme y enérgica. Hemos visto como. en tiempos de Enrique Dandolo. desafiaba a Inocencio III y recibia sin estremecerse las iras pontificales. Más tarde. en los siglos XIV y XV. por cuatro veces fué puesta en entredicho sin que esto provocara su turbación. Si aceplaba sin discusión los cánones del Concilio de Trento en materia de dogma, rehusó siempre las disposiciones disciplinarias que contrariaban las leyes venecianas: en ningún Estado europeo ejercieron menos influencia que en Venecia el clero y el papado. Para defender sus derechos y mantener su independencia, la República no se arredró por entrar en conflicto abierto con Roma. y es preciso constatar que en estas luchas, el gobierno fué sostenido por la casi totalidad del clero veneciano. reconocido a la Señoría por el cuidado con que atendia sus intereses y por la protección que le aseguraba contra la Santa Sede misma. En la ciudad de San Marcos, la Iglesia no cuidaba menos que los ciudadanos de la dignidad y de la grandeza del Estado, y jamás mostró extrañeza por que la República, en sus empresas más santas. considerara ante todo los intereses politicos de la ciudad.

EL PATRIOTISMO VENECIANO.- Todo esto se resuelve, finalmente, en un sentimiento de patriotismo muy elevado y muy fuerte. Desde la infancia. los patricios venecianos comprendian que inevitablemente tendrian un dia acceso a los cargos del Estado. y que inevitablemente llegarian a ser sus servidores. Toda la 
educación que recibian los preparaba para estas obligaciones futuras: toda su vida estaba consagrada a la gestión de los negocios públicos; y la ley. prohibiéndoles la renuncia de las magistraturas, imponiéndoles la asistencia asidua a los Consejos. era como la garantía de su consagración. Los que no pertenecian a las Tamilias nobles. los ciudadanos a quienes los beneficios de la industria y del comercio. el buen orden y la tranquilidad de la ciudad aseguraban una existencia a menudo afortunada y siempre fácil, no tenían menos estrecha unión con Venecia. En el interior de la ciudad, cada ciudadano se ocupaba igualmente de la salud y grandeza del Estado, no sólo por el halago de las recompensas prometidas a su celo. sino epor el ardor del cariño hacia la patria, (per zelo de amore per la patria). como decia aquel veneciano del siglo XV que, habiendo denunciando a un hombre culpable de haber robado algunas joyas del Tesoro, rehusó firmemente toda recompensa por un aclo que le parecia natural. En el extranjero, dedicarse incesantemente, gastar su fortuna, su energia, su inteligencia, trabajar constantemente por el interés y la gloria de Venecia,-asi luera, como Marco Polo, abriendo nuevas rutas al comercio. o. como los mercaderes que volvian de los mares levantinos, trayendo algo con que se embelleciera la ciudad, entregarse a acrecentar su poderio. enviándola acerca de todo lo que pudiera interesarla las más seguras informaciones, tal era el cuidado de todo veneciano. Desde 1268, el Senado habia ordenado a los embajadores que le enviaran, al regreso de su misión. relatos de conjunto, origen lejano de esas preciosas srelaciones,. en que lucen el buen sentido afinado y la agudeza de observación de los diplomáticos venecianos. Para servir a su país, nada ha sido enojoso a los venecianos, ni el espionaje, ni la intriga, ni el asesinato político mismo. Sin duda, es a veces necesario para aceptar algunas de estas obligaciones. un temple de alma duro, interesado y harto desprovisto de escrúpulos: pero hay en esta concepción de los deberes hacia la patria una belleza real por la intención que la inspira y por la abnegación de servir, noblemente aceptada.

Que se observe en todas las categorias, en todas las clases de la sociedad veneciana: en todas partes aparece el mismo sentimiento. Que se recorran los Anales de Malipiero, un soldado. los Diarii de Sanudo, un alto funcionario, el Diario de Priuli, mercader y banquero: una común inspiración penetra su obra: todos escriben para la gloria y el honor de San Marcos. ecuyo nombre, decia un embajador veneciano. cada uno de nosotros lleva grabado en el corazón. Estos no son sino algunos ejemplos; pero en todo veneciano, cualquiera que sea. una idea domina durante todo el curso de su vida: la República lo es todo y el individuo, nada.

LAS VIRTUDES DEL VENECIANO.-Se preguntará ahora cuáles virtudes esenciales aportaba el veneciano al servicio de su pais.

Al bosquejar anteriormente las figuras de un Enrique Dandolo y de un Marco Polo. se han señalado ya algunos de los rasgos más caracteristicos del espíritu veneciano: en uno de ellos. la ambición orgullosa y tenaz, la admirable bravura, el sentido político y la habilidad diplomática más maravillosa aún. la 
resolución y la agudeza, la previsión sutil y la iniciativa audaz; en el otro. la energía ingeniosa e infatigable. el sentido de los negocios y el afán de enriquecerse. el espiritu de empresa y el espíritu de observación: en los dos, análoga soberbia de ser originarios de la ciudad de San Marcos, una inteligencia flexible y fuerte para servir sus intereses, igual consagración a la patria veneciana. Los dos muestran un alma celosa de su independencia. muy poco embarazada por los prejuicios y los escrúpulos, una prudencia sagaz servida por una voluntad firme y por un sentido práctico extraordinariamente realista; los dos. sobrios de palabras, gustaron más de actuar que de discurrir. El placer de la acción útil es uno de los resortes del carácter veneciano.

EL DUX ANDRÉS DANDOLO.-Andrés Dandolo, dux desde 1543 hasta 1354. nos ofrece otro tipo igualmente representativo del espiritu veneciano. Descendiente de una de las más ilustres lamilias del patriciado. muy temprano habia desempeñado un papel en la ciudad: desde 1331. ocupó el alto cargo de procurador de San Marcos: doctor de Padua, había sido profesor de Derecho en la Universidad de aquella ciudad, y habia llegado a ner tan popular en Venecia-habia merecido. por su delicada gracia. el sobrenombre de II corfese-que en 1339. cuando aún no tenía treinta y dos años, se pensó en elegirle dux. Cuatro años más tarde alcanzó la magistratura suprema, en edad no acostumbrada. Pero las eminentes cualidades del hombre justificaban esta excepción sin precedentes. Sabio legista. escritor distinguido, gran patriota. disimulaba su juventud. según dice un cronista, epor la gravedad extraordinaria de sus costumbres y por la práctica de todas las virtudes. Pocos jefes del Estado veneciano tuvo más plena y alta conciencia de sus deberes; él mismo ha escrito en alguna parte que le agradaba más ser útil que mandar (prodesse quam praesse). Tuvo siempre una constante inquietud por el bien de sus súbditos y la prosperidad de la República. convencido, como él lo decía, de que el renombre del soberano se acrecienta tanto más gloriosamente cuanto con mayor atención vela por los intereses de los que gobierna. Aunque muy amigo de la paz. jamás trepidó en emprender las más grandes guerras siempre que el interés de Venecia pareció exiģirlo. cuando se trató. en la cruzada de 1345. de combatir a los turcos que amenazaban. de reprimir duramente en 1348 la revuelta de Zara. o de emprender contra Génova una lucha decisiva; y quedaba. se dijo. muerto de dolor por los desastres de la patria.

Andrés Dandolo, además de su papel político. hizo obra de legislador y de historiador. Era un hombre de letras, grande amigo de Petrarca: amaba también las artes, y fué él quien hizo decorar de mosaicos el baptisterio de San Marcos. Pero su actividad intelectual ofrece un carácter particular y significativo: el fin esencialmente práctico que siempre se propuso. Cuando hizo componer las dos compilaciones diplomáticas denominadas Liber albus y Liber blancus. lo que buscaba, al recopilar los más antiguos tratados suscriptos por los venecianos, era fundar sobre bases sólidas e indiscutibles los derechos y privilegios de la República. Lo que él pretendia, al referir en sus Anales la historia de la ciudad, era 
principalmente el exaltar su gloria. Su relato, que comienza con el apostolado de San Marcos, conserva minuciosamente y pone de relieve todo lo que puede servir a los intereses y a la grandeza de la patria. Dandolo insiste menudamente sobre los traslados de reliquias que aseguraron a la ciudad de las lagunas tantos santos protectores: insiste sobre los privilegios concedidos a la ciudad de San Marcos y sobre la ceremonia de los desposorios del Adriático. símbolo visible de su poder sobre los mares: señala todas las jornadas gloriosas. las de 1177 . las de 1204. que dieron a Venecia el prestigio y el imperio. Su historia, extraordinariamente tendenciosa, tiene, pues, una finalidad del todo práctica: forja las armas para justificar la politica de Venecia y para servir sus intereses. Como todos sus conciudadanos, el dux Dandolo, en cada uno de sus actos, no piensa sino en trabajar. según la fórmula citada, por el provecho y el honor de Venecias.

LA CULTURA INTELECTUAL.-Comprueba ésta en los venecianos el deseo de agregar ofra gloria, la de las arles y las letras, a todas aquéllas de que se enorgullecia la ciudad de San Marcos.

Los patricios de Venecia, en los siglos XIV y XV. eran gentes esclarecidas. cultivadas, amigas de las letras y de las artes, cuya flexible inteligencia juntaba, a las inquietudes de la politica y de la guerra. las nobles preocupaciones del hombre de gusto, del artista y del erudito. Señaladamente y con mucha injusticia. se ha exagerado la ignorancia de los nobles de Venecia y la indiferencia de la República por las cosas del espíritu. Ella prestaba buena acogida a los humanistas, a los griegos que venían entonces del Oriente a buscar asilo en Italia: desde fines del siglo XIV. Manuel Chrysoloras y Demetrio Kidones enseñaban el griego en Venecia: en el siglo XV recibió a Gemisto Pletón y a Jorge Trebizonda. a Filelfo y a Besarión, que, al morir, legó al Estado veneciano sus manuscritos. primer núcleo de la Biblioteca Marciana. Desde comienzos del siglo XV. la Universidad de Padua, reorganizada por Venecia, se desenvolvía magníficamente: y en la ciudad misma. la República mantenía cursos públicos de filosofia y de teologia, y un instituto de medicina. Desde 1469. la imprenta lué introducida en Venecia por Juan de Espira y su hermano Wendelino, a quienes se unió en 1470 el francés Nicolás Jenson. De tal manera. Venecia utilizaba los recursos que le ofrecian los paises extranjeros para la prosperidad y esplendor de la República.

En fin, el arte daba a la ciudad la más brillante apariencia. La Señoria tanto como los particulares. los ricos patricios como las corporaciones poderosas. los clérigos como los laicos. y. siguiendo su ejemplo. los mismos extranjeros. eslovacos, dálmatas, domiciliados en Venecia, emprendian la construcción de palacios, scuole, iglesias, decoradas por los grandes maestros de fines del siglo $\mathrm{XV}$. los dos Bellini y Carpaccio. No eran menos prósperas las industrias artísticas: la orfebrería, la escultura en madera, la cerámica, los fejidos preciosos. terciopelos y brocatos de oro. satisfacian magníficamente ese placer del lujo, tan caro a 
todos los venecianos, menos por su propia complacencia que por el esplendor que irradiaba sobre la patria.

En la iglesia de San Juan y San Pablo. panteón de la República veneciana, alinéanse, a lo largo de las murallas y contra las paredes del coro. las tumbas, maravilla de arte, en que reposan algunos de los más famosos de los dux de los siglos XIV y XV. El monumento de Miguel Morosini, muerto en 1382. es una de las obras más admirables que el arte gótico haya dejado en Venecia; el monumento de Pedro Mocenigo. muerto en 1476. el que tomó a Escutari y el que anexó a Chipre. del cual declara una orgullosa inscripción haber sido elevado econ los despojos de los enemigos, (ex hostium manubiis): el monumento de Andrés Vendramin. muerto en 1478. el más bello talvez de los que se admiran en Venecia. Además, en San Marcos, en Santa Maria de Frari, otras sepulturas gloriosas recuerdan otros héroes famosos. Y. aún. son las estatuas erigidas sobre las plazas o en el interior de las iglesias, en honor de los generales ilusfres, de los condottieri famosos, un Savelli. un Colleone, que habian servido bien a la República. A todos, con liberalidad. Venecia demostró su reconocimiento. Confió a los más grandes artistas, a los Lombardi, los Leopardi, los Rizzo. los Verrocchio, el cuidado de eternizar su memoria. Les dió. en vida, gran participa. ción en el gobierno y en las allas dignidades: muertos, los glorificó en admirables esculturas, porque todos ellos habian sido los artesanos fieles consagrados a su grandeza, porque el mayor cuidado de su vida habia sido trabajar epor el provecho y el honor de Venecia. 